\title{
Prediction of outcome in patients presenting with fatigue in primary care
}

Iris Nijrolder, Daniëlle van der Windt and Henriëtte van der Horst

\begin{abstract}
Background

Although fatigue is a common problem presenting to primary care, few prospective studies have examined the contribution of a wide range of prognostic factors. Aim

To determine the combination of factors most strongly associated with a favourable or unfavourable course of fatigue, when fatigue is presented as a main symptom in primary care.

\section{Design of study}

Prospective, observational cohort study with a 1-year follow-up.

Setting

A total of 147 primary care practices in the Netherlands.

Method

Patients presenting with fatigue as a main symptom completed questionnaires at baseline, and 1, 4, 8, and 12 months later. The prognostic value of potential predictors was assessed by applying multivariable logistic regression analysis. The outcome was severity of fatigue, defined as a combination of dichotomised scores on several repeated measurements with the Checklist Individual Strength. Separate models were used to predict either a favourable or an unfavourable course of fatigue.
\end{abstract}

\section{Results}

Baseline severity of fatigue and patient expectations of chronicity consistently predicted a poor outcome. Additional factors predicting a chronic course were baseline pain intensity and less social support. Baseline characteristics predicting a fast recovery were: male sex, not providing care for others (for example, for older people), better perceived health, and fewer (serious) prolonged difficulties. Both models had good reliability and discriminative validity (area under the receiver operating characteristic curve after internal validation: 0.78 and 0.79 ).

\section{Conclusion}

The identified combination of predictors reflects the multidimensionality of fatigue, with a significant contribution of patient expectations of chronicity in the prediction of a poor prognosis. These negative perceptions are modifiable, and should receive more attention in the initial assessment of patients presenting with fatigue.

\section{Keywords}

cohort study; epidemiologic factors; fatigue, perception; primary health care; prognosis.

\section{INTRODUCTION}

Fatigue is a common problem presenting to primary care..$^{1-4}$ In many cases, there is no apparent explanatory or accompanying disorder, and many patients do not return to visit the GP. However, the results of previous studies indicate that more than half of patients do not show a favourable course..$^{3,5,6}$ It is likely that the occurrence and persistence of this nonspecific symptom is determined by multiple factors. Nonetheless, a systematic review of the literature revealed that only a few prospective studies in primary care have investigated the contribution of different prognostic factors; these studies did not include factors like lifestyle and social factors. The possibility of building a prognostic model also depends on the sample size; most of the studies that have been performed had fairly small study populations. Furthermore, few studies enrolled patients who presented with fatigue as a main symptom. ${ }^{7}$

To improve GPs' history taking and management of this frequently presented non-specific symptom, it is important to know which factors are likely to be relevant in predicting the outcome of an episode of fatigue. The aim of this study was to include a sufficiently large sample to investigate which combination of factors predicts a favourable or unfavourable course of fatigue when presented as a main symptom in primary care. A wide range of potential prognostic factors was

I Nijrolder, MSc, epidemiologist; D van der Windt, $P h D$, associate professor in primary care epidemiology; $\mathrm{H}$ van der Horst, $P h D, M D$, professor in general practice, EMGO Institute, VU University Medical Centre, Amsterdam, the Netherlands.

Address for correspondence

Iris Nijrolder, EMGO Institute, VU University Medical Centre, Van der Boechorststraat 7, 1081 BT Amsterdam, the Netherlands. E-mail: i.nijrolder@vumc.nl

Submitted: 14 March 2008; Editor's response: 6 May 2008; final acceptance: 24 November 2008.

(C) British Journal of General Practice

This is the full-length article of an abridged version published in print. Cite this article as: Br J Gen Pract 2009; DOI: 10.3399/bjgp09X420329 
investigated, by addressing sociodemographic factors, fatigue characteristics, and somatic, psychological, social, and lifestyle factors.

\section{METHOD}

\section{Design and recruitment}

An observational cohort study of adult patients presenting with fatigue as a main symptom was conducted in 147 practices across the Netherlands. From June 2004 to January 2006, 111 GPs and 57 GP trainees recruited patients with a new episode of fatigue. This implied that the patient had neither visited the GP before for the same episode of fatigue, nor visited for a previous episode within the past 6 months. Patients who were receiving or had received chemotherapy or radiotherapy during the 3 months before the consultation, and women who were pregnant or less than 3 months' postpartum, were excluded. Eligible patients were informed by their GP about the study and invited to participate. If interested, they were sent an information letter and the baseline questionnaire. Patients were enrolled if they then returned the signed consent form. Participants completed these questionnaires shortly after the consultation (baseline), and at 1, 4, 8, and 12 months after baseline.

\section{Definition of outcome}

Outcome was defined in terms of both recovery and chronicity, assessed with the severity scale of the Checklist Individual Strength (CIS). ${ }^{8}$ The CIS is a $20-$ item questionnaire that has been validated in several study populations with fatigue in the Netherlands, and recently in Taiwan and Japan (7 point Likert scale from 'Yes, true' to 'No, not true'). A score of 34 or higher on the eight-item subscale for subjective fatigue has often been used as a cut-off point for severe fatigue..$^{9,10}$ Both of the study's outcome definitions were based on multiple outcome measurements during follow-up. Recovery was defined as a score $<34$ on the severity scale of the CIS at 4, 8, and 12 months after baseline. An unfavourable course (chronic fatigue) was defined as a score $\geq 34$ on the CIS severity scale at three or all of the four follow-up measurements. Patients with missing measurements during follow-up were only classified as recovered or chronically fatigued if sufficient measurements were available.

\section{Potential predictors}

Patient characteristics at baseline that were analysed as potential predictors were demographic factors, fatigue characteristics, physical activity, perceptions, health-related factors, and social and lifestyle factors, obtained from the postal questionnaire. If available for a particular factor, validated questionnaires were used to measure these factors ${ }^{11-17}$ (Table 1). Data on

\section{How this fits in}

Fatigue is a non-specific multidimensional symptom that is common in primary care. The few available studies indicate that a large percentage of patients show an unfavourable course, but evidence on the predictive value of potential prognostic factors is scarce. This study shows that severity of fatigue and patient expectations of chronicity are the strongest predictors of poor outcome in patients presenting with fatigue as a main symptom.

relevant chronic diseases, malignancies, and functional syndromes were obtained from the GPs' medical records.

\section{Statistical analysis}

Logistic regression analysis was applied to determine the combination of factors that best predicted the outcome of fatigue. Two separate models were built using two different outcome measures: recovery and chronicity. All patients from the total cohort providing sufficient data to define outcome were included in the models.

First, univariate analysis was performed to examine the relationship between each potential predictor and outcome. For continuous variables, linearity of the associations with outcome was checked. If there was no linear trend, the variable was divided into categories: if possible based on existing cut-off points, otherwise in tertiles. Variables with $P$-value $<0.20$ (Wald statistic) were considered to be potential candidates for the multivariate analysis.

Next, correlations between candidate variables were assessed. If there were strong inter-correlations $(r 0.50)$, variables with weaker associations with outcome, or variables measuring a very similar construct, were excluded from the multivariate analysis. As the number of variables exceeded onetenth of the number of patients with the outcome of interest, variables were entered in blocks, mainly adhering to the sequence of history taking in primary care (demographic factors first, followed by fatigue characteristics, then perceptions, health, and other symptoms, and finally lifestyle and social factors). Variables with a $P$-value $>0.10$ (Wald statistic) were removed manually in a stepwise backwards procedure, until all variables showed a significant association with outcome $(P<0.10)$.

\section{Evaluation of the models}

The reliability of the models was determined by calibrating the observed frequencies against the predicted outcome probabilities in a calibration plot. ${ }^{18}$ In this plot, perfect agreement between predicted and observed values results in a $45^{\circ}$ line with a slope equal to 1 and an intercept equal to 0 . In addition, the 


\section{Table 1. Instruments used for measurement of prognostic variables.}

\begin{tabular}{|c|c|c|c|}
\hline \multirow{2}{*}{ Fatigue } & \multirow[t]{2}{*}{ Subscales used (number of items) } & Scale & Zange of final scores \\
\hline & & & \\
\hline Checklist Individual Strength (CIS), ${ }^{8}$ & Severity (8) & 7-point Likert scales 'yes, that is true' & $8-56$ \\
\hline \multirow{2}{*}{ questions refer to the past 14 days } & Concentration (5) & and 'no, that is not true' & $5-35$ \\
\hline & Motivation (4) & & $4-28$ \\
\hline \multicolumn{4}{|l|}{ Perceptions } \\
\hline $\begin{array}{l}\text { Illness Perception Questionnaire - Revised } \\
\left(\text { IPQ-R) }{ }^{11} \text { translated into Dutch }\right.\end{array}$ & Personal control (6) & $\begin{array}{l}\text { 5-point Likert scales, 'don't agree } \\
\text { at all' to 'agree very much' }\end{array}$ & $5-30$ \\
\hline Coherence: insight into fatigue symptoms & Coherence (6) & & $5-30$ \\
\hline Timeline: expectations of chronicity & Timeline (6) & & $5-30$ \\
\hline Consequences: impact of fatigue & Consequences (5) & & $5-25$ \\
\hline $\begin{array}{l}\text { Attributions (viral/germ, altered immunity, } \\
\text { diet/eating habits; dichotomised for analysis) }\end{array}$ & Psychological attribution $^{a}(6)$ & $\begin{array}{l}\text { 5-point Likert scale, 'don't agree } \\
\text { at all' to 'agree very much' }\end{array}$ & $6-30$ \\
\hline \multicolumn{4}{|l|}{ Health and other symptoms } \\
\hline Short Form health survey $-36^{12}$ & General Health (5) & $\begin{array}{l}\text { 5-point Likert scale, 'very well' to 'bad', } \\
\text { and 'very true' to 'very untrue' }\end{array}$ & $0-100$ \\
\hline Pain: questions refer to the past month & Pain (2) & $\begin{array}{l}\text { 6-point Likert scale, 'no' to 'very severe' and } \\
5 \text {-point scale 'not at all' to 'very much' }\end{array}$ & $0-100$ \\
\hline \multirow{4}{*}{$\begin{array}{l}\text { Four-Dimensional Symptom Questionnaire, }{ }^{13} \\
\text { questions refer to the past week }\end{array}$} & Distress (16) & 5-point Likert scales, 'don't agree & $0-32$ \\
\hline & Depression (6) & at all' to 'agree very much' & $0-12$ \\
\hline & Anxiety (12) & & $0-24$ \\
\hline & Somatisation (16) & & $0-32$ \\
\hline $\begin{array}{l}\text { From the IPQ-R: number of symptoms } \\
\text { experienced since the start of fatigue }\end{array}$ & List of 13 symptoms & Yes/no & $0-13$ \\
\hline $\begin{array}{l}\text { Symptom Checklist, }{ }^{14} \text { questions refer to } \\
\text { the past week }\end{array}$ & Sleep (3) & $\begin{array}{l}\text { 5-point Likert scales, } \\
\text { 'not at all' to 'very much' }\end{array}$ & $0-15$ \\
\hline
\end{tabular}

Physical activity

Short QUestionnaire to ASsess

Health-enhancing physical activity (SQUASH), ${ }^{15}$

questions refer to the past week

Number of days of moderate-intensity physical activity for at least 30 minutes from subscales Physical activity at work/ school and in household

Social factors

Checklist for long-term difficulties (adapted from Groningse Lijst Langdurige Moeilijkheden, Dutch ${ }^{16}$ ), questions refer to "lately experienced chronic difficulties'

Checklist for life events (adapted from Groningse Gebeurtenissen Lijst, Dutch ${ }^{16}$ ), questions refer to the past 12 months Social Support Scale ${ }^{17}$
List of 12 domains in which

4-point Likert scale for severity chronic difficulties may be experienced; (no difficulties to severe difficulties) three boxes leave room for additional difficulties

List of 28 life events within 8 domains. Three boxes leave room for additional life events

12 items
Yes/no

5-point Likert scale, 'Yes, very clear' to 'No, certainly not'
$0-7$

Number of days and average

hours or minutes per day

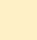

Subscale developed based on IPQ-R attribution items (stress or worry, my own behaviour, my mental attitude, family problems or worry, my emotional state, my personality); Cronbach's alpha 0.80 .

Hosmer-Lemeshow goodness-of-fit statistic was used to test whether there was any significant difference between predicted and observed values.

The discriminative ability of the models was assessed by calculating the area under the receiver operating characteristic curve. A value of 1 for the area under the curve (AUC) indicates optimal discrimination between people with and without the outcome of interest, whereas a value of 0.5 indicates no discrimination above chance..$^{19}$

The internal validity of the models was assessed with a bootstrapping procedure (200 samples) to correct the AUC for over-optimism, in order to obtain an estimation that better reflects model performance in another, but similar population of patients with fatigue. ${ }^{19,20}$ These analyses were performed using Rstatistics software (version 2.5.0).

\section{RESULTS}

\section{Response}

GPs enrolled 856 patients; 642 consented to participate and completed the first questionnaire (response rate $75 \%$ ). Baseline characteristics are presented in Table 2. Mean age was 42 years, and around $60 \%$ of the patients had been fatigued for at least 6 months. Reasons for non-response were given by 127 patients $(60 \%$ of those who did not participate), and the most frequently mentioned 
reasons were recovery from fatigue $(43 \%)$ or lack of time or interest (32\%); $8 \%$ reported that they were too tired, $4 \%$ were not eligible, and $13 \%$ were unwilling to participate for other reasons. On average, participants were 5 years older $(P<0.01)$ and included more women $(73 \%$ versus $65 \%, P<0.05)$ compared to non-participants. During follow-up, the completion rates varied between $82 \%$ and $88 \%$. No difference was found in fatigue severity or sex ratio between completers and non-completers, but the completers were, on average, 8 years younger $(P<0.01)$. Sufficient data were available to identify 561 patients with a favourable outcome, and 535 patients with an unfavourable outcome.

\section{Favourable course: recovery within 4 months}

A total of 132 patients (24\%) showed a favourable course of fatigue. Outcome predictors are presented in Table 3. Of 41 potential variables, 26 showed a significant association $(P<0.20)$ in the univariate analysis and were entered in blocks in a multivariate model. The following combination of factors was most strongly associated with a favourable course: not providing informal care for others, less severe fatigue at baseline, no expectations of chronicity, less (serious) prolonged difficulties, male sex, and better perceived health. The AUC increased from 0.60 , based on the first block (demographic variables only), to 0.79 (95\% confidence interval $[\mathrm{Cl}]=0.74$ to 0.83 ) for the final model; most of the subsequent gain in discriminative ability was obtained after adding the second block, which included characteristics of fatigue (AUC 0.76). The corrected AUC after internal validation was 0.78 .

The reliability of the model was good; the calibration plot (Figure 1) shows that the observed and predicted probabilities of a positive outcome were fairly close to the $45^{\circ}$ line. The Hosmer-Lemeshow statistic showed no significant difference between observed and predicted values $(P=0.22)$.

\section{Unfavourable course: (near) chronicity}

A total of 231 patients $(43 \%)$ showed an unfavourable course of fatigue. Twenty-nine variables showing a significant univariate association were entered in blocks in the multivariate model. Prognostic factors that were retained in the model were severity of fatigue, expectations of chronicity, more pain, and less social support (Table 3). The AUC increased from 0.57 to $0.80(95 \% \mathrm{Cl}=0.76$ to 0.84 ) in the final model; again, baseline characteristics of fatigue contributed most to the predictive performance $(A \cup C=0.74)$. The corrected AUC after internal validation was 0.79 . The reliability of this model was confirmed by visual inspection of the calibration plot (Figure 2) and by the Hosmer-Lemeshow statistic $(P=0.38)$.

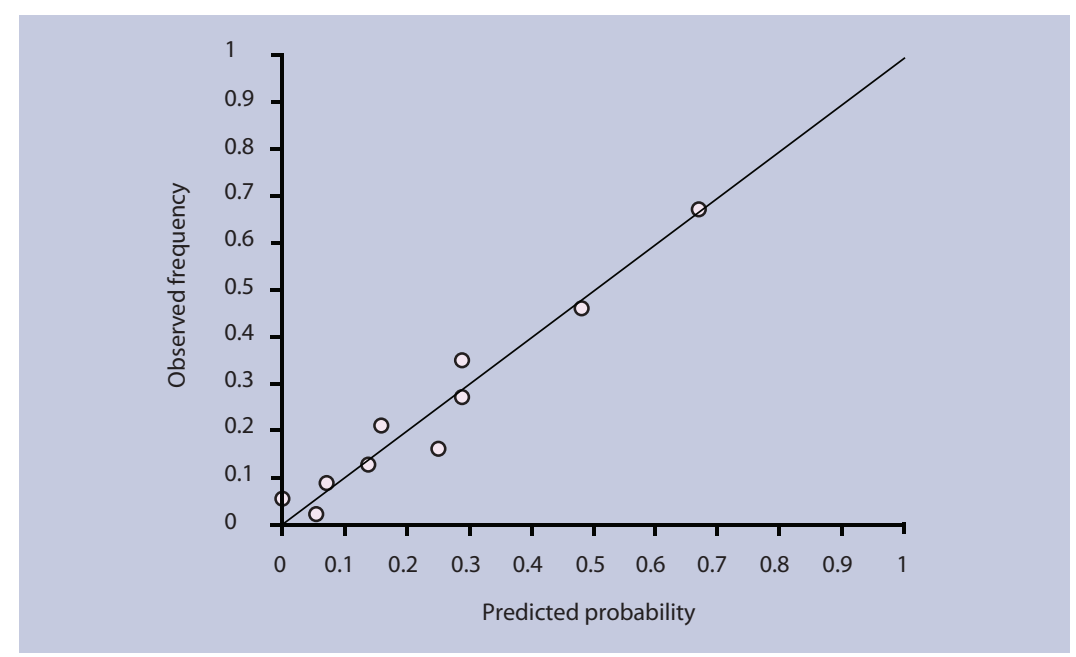

\section{Chronic disease}

In the total cohort, 60 patients ( $11 \%$ of 525$)$ had a chronic condition that could be considered to be present at the time of consultation, notably asthma or chronic obstructive pulmonary disease $(n=37$, $7 \%$ ) or diabetes $(n=17,3 \%)$. Fourteen patients $(3 \%)$ had a malignancy in their medical history, and 20 patients (4\%) had a functional syndrome, most often irritable bowel syndrome $(n=17,3 \%)$. Within the group showing an unfavourable course, 26 patients (14\% of 190 with available data on comorbidity) had a chronic condition, compared to 11 patients (10\% of 112 ) in the group showing a favourable course. Because data on comorbidity were not available for $17 \%$ of the patients, chronic disease was not included in the prognostic analysis.

\section{DISCUSSION}

\section{Summary of main findings}

During the year following the consultation, a minority of the patients reported recovery within 4 months, while a substantial number of patients showed an unfavourable course. The combination of factors that

Figure 1. Calibration plot for prediction of a favourable course of fatigue.

Figure 2. Calibration plot for prediction of an unfavourable course of fatigue.

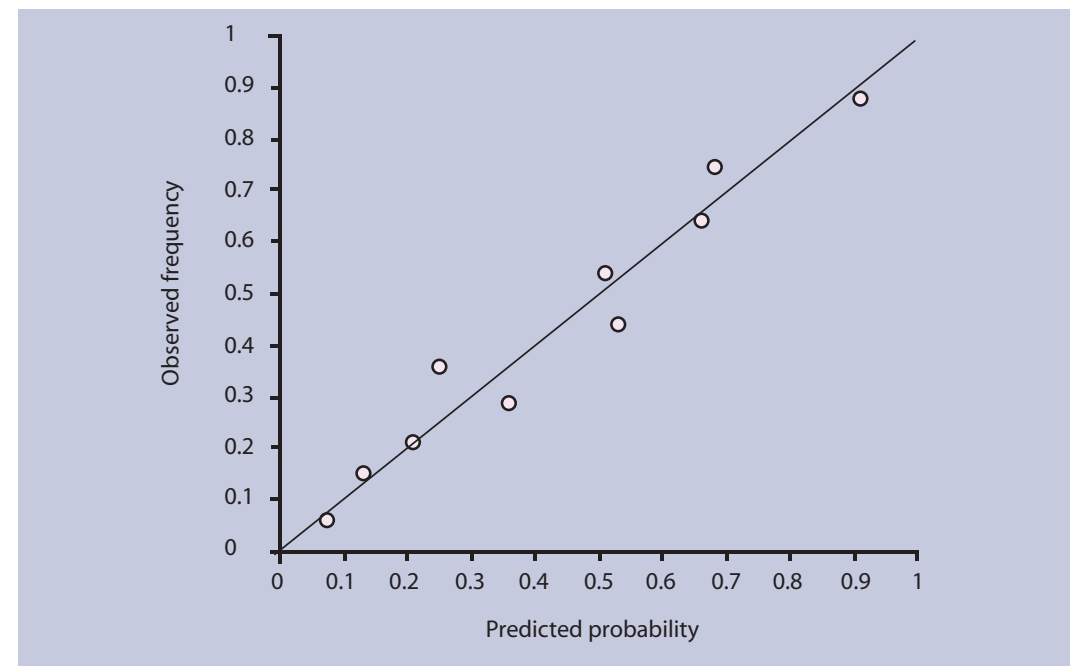




\begin{tabular}{|c|c|c|c|}
\hline Demographics & $\begin{array}{l}\text { Total population, } \\
\qquad n=642\end{array}$ & $\begin{array}{l}\text { Fast recovery, } \\
n=132 \text { of } 561\end{array}$ & $\begin{array}{c}\text { (Near) chronicity, } \\
n=231 \text { of } 535\end{array}$ \\
\hline Sex, female, $n(\%)$ & $467(73)$ & $84(64)$ & $178(77)$ \\
\hline Age in years, mean (SD) & $42(16)$ & $43(15)$ & $45(17)$ \\
\hline \multicolumn{4}{|l|}{ Education, $n$ (\%) } \\
\hline Primary & $40(6)$ & $6(5)$ & $19(8)$ \\
\hline Secondary & $483(75)$ & $102(77)$ & $173(75)$ \\
\hline Tertiary & $118(18)$ & $24(18)$ & $38(17)$ \\
\hline \multicolumn{4}{|l|}{ Care responsibilities, $n(\%)$} \\
\hline Care for children & $241(38)$ & $56(43)$ & $83(36)$ \\
\hline Care for children $<5$ years old & $103(16)$ & $23(17)$ & $31(14)$ \\
\hline Care for other people, e.g. older people & $63(10)$ & $4(3)$ & $27(12)$ \\
\hline Employed, $n(\%)$ & $492(77)$ & $107(81)$ & $160(69)$ \\
\hline Hours of work (paid + unpaid) per week, mean (SD) & $41(26)$ & $44(19)$ & $40(29)$ \\
\hline$<30$ hours, $n(\%)$ & $182(28)$ & $23(17)$ & 77 (34) \\
\hline $30-50, n(\%)$ & $277(43)$ & $66(50)$ & $97(42)$ \\
\hline$\geq 50, n(\%)$ & $183(29)$ & $43(33)$ & $56(24)$ \\
\hline Living together/married, $n(\%)$ & $411(64)$ & $85(64)$ & $144(63)$ \\
\hline \multicolumn{4}{|l|}{ Fatigue } \\
\hline Severity, CIS, mean (SD) & $45.8(8.4)$ & $41.4(9.5)$ & $48.9(6.5)$ \\
\hline Less concentration, CIS, mean (SD) & $21.3(8.7)$ & $16.1(6.0)$ & $22.5(8.7)$ \\
\hline Less motivation, CIS, mean (SD) & $16.9(6.2)$ & $18.7(8.3)$ & $17.6(6.3)$ \\
\hline \multicolumn{4}{|l|}{ Duration, $n(\%)$} \\
\hline$<1$ month & $44(7)$ & $15(12)$ & $15(7)$ \\
\hline $1-3$ months & $98(16)$ & $32(25)$ & $20(9)$ \\
\hline $3-6$ months & $115(19)$ & $28(22)$ & $40(18)$ \\
\hline $6-12$ months & $114(18)$ & $21(16)$ & $39(17)$ \\
\hline$\geq 1$ year & $252(40)$ & $34(26)$ & $112(50)$ \\
\hline \multicolumn{4}{|l|}{ Onset of fatigue episode, $n$ (\%) } \\
\hline Sudden & $111(17)$ & $28(21)$ & $37(16)$ \\
\hline Gradual & $527(82)$ & $104(78)$ & $191(84)$ \\
\hline
\end{tabular}

..continued

best predicted the course of fatigue reflected different dimensions: demographics, fatigue characteristics, perceptions, general health, psychological, and social factors. This corresponds well with the concept that fatigue is a multidimensional problem. Consistent and significant predictors of an unfavourable outcome in both models were baseline severity of fatigue and patient expectations of chronicity.

\section{Strengths and limitations of the study}

Instead of measuring the outcome at one moment in time, the outcomes of repeated measurements during 1 year were combined to define a favourable or unfavourable course. This may have resulted in a more stable outcome, and thus have strengthened the results. Separate analyses were performed for patients with either a good or a poor outcome, because this provided information about relevant subgroups of patients, and may help GPs in their decision making with regard to management of the problem.

By assessing the relative contribution of a variety of potentially relevant prognostic factors, addressing somatic, psychological, and social problems, the multidimensional nature of the symptom was taken into account. Although some potential predictors may have been missed (for example, occupational factors or spiritual beliefs), the study included a variety of factors that can be measured by means of questionnaires in a large-scale observational cohort study. Clinical management could also account for variation in outcome. Although self-report data on treatment were collected, it was decided not to use this information in the prognostic models. In this observational study, confounding by indication would result in misleading information about the predictive value of management decisions.

Although the drop-out rate was low it was not possible to define the course of fatigue in each patient. It is unlikely, however, that this has strongly affected the composition of our prognostic models. Furthermore, notwithstanding the performance of the models, the results need to be validated in other populations of patients presenting with fatigue. Apart 
Table 2 continued. Baseline characteristics of patients presenting with fatigue in general practice.

\begin{tabular}{|c|c|c|c|}
\hline Fatigue continued & $\begin{array}{l}\text { Total population, } \\
\qquad n=642\end{array}$ & $\begin{array}{l}\text { Fast recovery, }{ }^{\text {a }} \\
n=132 \text { of } 561\end{array}$ & $\begin{array}{l}\text { (Near) chronicity, } \\
n=231 \text { of } 535\end{array}$ \\
\hline \multicolumn{4}{|l|}{ Previous episodes, $n$ (\%) } \\
\hline Yes & 417 (65) & $66(50)$ & $163(71)$ \\
\hline Yes, with duration $<6$ months & $246(38)$ & $46(35)$ & $76(33)$ \\
\hline Yes, with duration $\geq 6$ months & $171(27)$ & $20(15)$ & $87(38)$ \\
\hline \multicolumn{4}{|l|}{ Localisation, $n(\%)$} \\
\hline Primarily extremities & $56(9)$ & $19(14)$ & $19(8)$ \\
\hline Primarily head & $111(17)$ & $29(22)$ & $29(13)$ \\
\hline Whole body, or head and extremities & 407 (64) & $70(53)$ & $162(70)$ \\
\hline Not clear & $66(10)$ & $14(11)$ & $21(9)$ \\
\hline \multicolumn{4}{|l|}{ Perceptions, IPQ-R, mean (SD) } \\
\hline Personal control, range 6-30 & $18.6(3.7)$ & $19.2(3.7)$ & $17.9(3.8)$ \\
\hline Understanding of the fatigue, range $5-25$ & $13.7(4.2)$ & $14.1(4.2)$ & $13.2(4.1)$ \\
\hline Expectation of a chronic course, range $6-30$ & $17.4(4.5)$ & $15.2(3.6)$ & $19.4(4.6)$ \\
\hline Impact of fatigue, range 6-29 & $16.4(4.3)$ & $14.4(3.9)$ & $18.0(4.3)$ \\
\hline \multicolumn{4}{|l|}{ Treatment (self-report), $n(\%)$} \\
\hline Treatment for fatigue & $52(8)$ & $8(6)$ & $28(12)$ \\
\hline Treatment for other reasons & $181(28)$ & $38(29)$ & $76(33)$ \\
\hline Medication & $146(23)$ & $32(24)$ & $57(25)$ \\
\hline Psychologist or social work & $44(7)$ & $8(6)$ & $22(10)$ \\
\hline Physiotherapy or manual therapy & $63(10)$ & $9(7)$ & $32(14)$ \\
\hline Alternative/complementary treatment & $40(6)$ & $11(8)$ & $13(6)$ \\
\hline \multicolumn{4}{|c|}{ Daily activity and lifestyle } \\
\hline \multicolumn{4}{|c|}{$\begin{array}{l}\text { Physical activity: SQUASH; number of days of moderate } \\
\text { intensity physical activity for at least } 30 \text { minutes }\end{array}$} \\
\hline Mean (SD) & $2.8(2.4)$ & $3.1(2.2)$ & $2.8(2.5)$ \\
\hline 0 days, $n(\%)$ & 147 (23) & $22(17)$ & $54(23)$ \\
\hline $1-4$ days, $n(\%)$ & $319(50)$ & $70(53)$ & $113(49)$ \\
\hline$\geq 5$ days, $n(\%)$ & $175(27)$ & $39(30)$ & $64(28)$ \\
\hline \multicolumn{4}{|l|}{ Alcohol, units per week, $n$ (\%) } \\
\hline$<1$ & 334 (52) & $59(45)$ & $131(57)$ \\
\hline $1-10$ & $253(40)$ & $64(49)$ & $80(35)$ \\
\hline$>10$ & $54(9)$ & $9(7)$ & $20(10)$ \\
\hline \multicolumn{4}{|l|}{ Smoking, $n$ (\%) } \\
\hline No, never smoked & $253(40)$ & $56(42)$ & $89(39)$ \\
\hline Not currently, or sometimes & $242(38)$ & $52(39)$ & $85(37)$ \\
\hline Yes, daily & $145(23)$ & $24(18)$ & $56(24)$ \\
\hline
\end{tabular}

from perceived health, no factors were found that were positively associated with a fast recovery. However, the contribution of negative perceptions to prognosis would imply that positive (or neutral) perceptions would have a positive effect on the course of fatigue. Investigating (coping) behaviour, patterns of activity, and diet in future studies could reveal additional prognostic factors that are potentially modifiable and may provide alternative starting points for the development of interventions.

\section{Comparison with existing literature}

Baseline severity of fatigue has been found to be a prognostic factor in other studies in primary care, ${ }^{21}$ and in the community. ${ }^{9,22,23}$ Duration of fatigue was found to be a prognostic indicator of outcome in other studies, ${ }^{6,24}$ but was not retained in the present study model; neither was localisation of fatigue. Both characteristics are apparently strongly related to severity, but their contribution was not significant in combination with fatigue severity.

Rather than fatigue duration at baseline, patient expectations of chronicity significantly predicted an unfavourable course of fatigue in both models. Similar results have been found in a previous study in primary care for poor fatigue outcome after 6 months..$^{25}$ Furthermore, more personal control or self-efficacy has been shown to be associated with a better prognosis in fatigued employees on sick leave, ${ }^{26}$ and patients with chronic fatigue syndrome, ${ }^{27}$ which may 
Table 3. Predictors of outcome in patients presenting with fatigue in general practice.

\begin{tabular}{|c|c|c|c|c|c|c|}
\hline & \multicolumn{3}{|c|}{ Favourable course, $n=561$} & \multicolumn{3}{|c|}{ Unfavourable course, $n=535$} \\
\hline & $\begin{array}{c}\text { Univariate OR } \\
(95 \% \mathrm{Cl})\end{array}$ & $P$-value ${ }^{\mathrm{a}}$ & $\begin{array}{c}\text { Multivariate OR } \\
(95 \% \mathrm{Cl}) ; \mathrm{A} \cup \mathrm{C} 0.79\end{array}$ & $\begin{array}{l}\text { Univariate OR } \\
\quad(95 \% \mathrm{Cl})\end{array}$ & $P$-value ${ }^{a}$ & $\begin{array}{c}\text { Multivariate OR } \\
(95 \% \mathrm{Cl}) ; \mathrm{A} \cup \mathrm{C} 0.80\end{array}$ \\
\hline \multicolumn{7}{|l|}{ Demographic } \\
\hline Sex, female versus male & 0.51 (0.33 to 0.77$)$ & $0.001^{\mathrm{a}}$ & $0.64(0.40$ to 1.03$)$ & 1.46 (0.98 to 2.16$)$ & $0.059^{\mathrm{a}}$ & \\
\hline Age per year older & & & & 1.01 (1.00 to 1.02$)$ & $0.059^{\mathrm{a}}$ & \\
\hline $31-50$ versus $18-30$ & 1.44 (0.87 to 2.39$)$ & 0.16 & & & & \\
\hline $51-89$ versus $18-30$ & 1.40 (0.81 to 2.42$)$ & 0.24 & & & & \\
\hline \multicolumn{7}{|l|}{ Education } \\
\hline Secondary versus primary & 1.44 (0.58 to 3.57$)$ & 0.44 & & 0.66 (0.33 to 1.32$)$ & 0.24 & \\
\hline Tertiary versus primary & 1.33 (0.49 to 3.61$)$ & 0.57 & & $0.48(0.22$ to 1.04$)$ & 0.062 & \\
\hline \multicolumn{7}{|l|}{ Care responsibilities } \\
\hline Care for children $<5$ years old, yes & 1.01 (0.60 to 1.69$)$ & 0.98 & & $0.80(0.49$ to 1.30$)$ & 0.37 & \\
\hline Care for others, e.g. older people, yes & 0.24 (0.09 to 0.68$)$ & $0.004^{\mathrm{a}}$ & $0.23(0.07$ to 0.71$)$ & 1.39 (0.79 to 2.43$)$ & 0.26 & \\
\hline Hours of work per week & $1.01(1.00$ to 1.01$)$ & 0.23 & & $1.00(0.99$ to 1.00$)$ & 0.22 & \\
\hline Employed, yes & 1.70 (1.03 to 2.79$)$ & $0.048^{\mathrm{a}}$ & & $0.63(0.42$ to 0.93$)$ & $0.023^{\mathrm{a}}$ & \\
\hline Married or living together, yes & 0.91 (0.61 to 1.38$)$ & 0.67 & & $0.86(0.60$ to 1.23$)$ & 0.41 & \\
\hline \multicolumn{7}{|l|}{ Fatigue } \\
\hline Fatigue severity, CIS, ppi & 0.91 (0.89 to 0.93 ) & $<0.001^{\mathrm{a}}$ & $0.93(0.90$ to 0.96$)$ & $1.10(1.07$ to 1.13$)$ & $<0.001^{\text {a }}$ & 1.08 (1.05 to 1.11$)$ \\
\hline Less concentration, CIS, ppi & 0.96 (0.94 to 0.98$)$ & $<0.001^{\text {a }}$ & & 1.04 (1.02 to 1.06$)$ & $<0.001^{\text {a }}$ & \\
\hline Less motivation, CIS, ppi & $0.97(0.94$ to 1.00$)$ & $0.066^{\mathrm{a}}$ & & $1.03(1.00$ to 1.06$)$ & 0.024 & \\
\hline \multicolumn{7}{|l|}{ Duration } \\
\hline $3-6$ months versus $<3$ months & $0.68(0.39$ to 1.19$)$ & 0.18 & & 1.80 (1.03 to 3.15$)$ & 0.039 & \\
\hline $6-12$ months versus $<3$ months & $0.47(0.26$ to 0.86$)$ & 0.013 & & 2.00 (1.13 to 3.52$)$ & 0.017 & \\
\hline$\geq 12$ months versus $<3$ months & $0.32(0.19$ to 0.54$)$ & $<0.001$ & & $3.13(1.95$ to 5.04$)$ & $<0.001$ & \\
\hline Previous episodes, yes & $0.42(0.28$ to 0.63$)$ & $<0.001^{a}$ & & $1.41(0.98 \text { to } 2.03)^{\mathrm{a}}$ & $0.067^{\mathrm{a}}$ & \\
\hline Onset, sudden versus gradual & 0.66 (0.40 to 1.08$)$ & $0.096^{a}$ & & 0.99 (0.62 to 1.58$)$ & 0.97 & \\
\hline $\begin{array}{l}\text { Fatigue in whole body or several body } \\
\text { parts versus locally, only head or limbs }\end{array}$ & $0.53(0.36$ to 0.79$)$ & $0.001^{\mathrm{a}}$ & & $1.67(1.16 \text { to } 2.40)^{\mathrm{a}}$ & $0.005^{\mathrm{a}}$ & \\
\hline \multicolumn{7}{|l|}{ Perceptions } \\
\hline \multicolumn{7}{|l|}{ IPQ-R } \\
\hline Personal control, ppi & 1.06 (1.01 to 1.12$)$ & 0.026 & & $0.91(0.87 \text { to } 0.96)^{\mathrm{a}}$ & $<0.001^{\mathrm{a}}$ & \\
\hline Coherence of fatigue symptoms, ppi & 1.03 (0.98 to 1.08$)$ & 0.21 & & $0.94(0.90 \text { to } 0.98)^{\mathrm{a}}$ & $0.003^{\mathrm{a}}$ & \\
\hline Expectations of chronicity, ppi & 0.84 (0.80 to 0.89$)$ & $<0.001^{\mathrm{a}}$ & 0.88 (0.83 to 0.93$)$ & $1.23(1.17 \text { to } 1.29)^{\mathrm{a}}$ & $<0.001^{\text {a }}$ & 1.19 (1.13 to 1.25$)$ \\
\hline Negative consequences, ppi & 0.85 (0.81 to 0.90$)$ & $<0.001^{\text {a }}$ & & $1.18(1.13 \text { to } 1.24)^{\mathrm{a}}$ & $<0.001^{\text {a }}$ & \\
\hline Psychological attribution, ppi & 0.94 (0.90 to 0.98$)$ & $0.007^{\mathrm{a}}$ & & 1.02 (0.99 to 1.06$)$ & 0.23 & \\
\hline Viral/germ attribution, yes & 1.32 (0.85 to 2.05$)$ & 0.22 & & $0.84(0.57$ to 1.25$)$ & 0.40 & \\
\hline Altered immunity attribution, yes & 0.66 (0.43 to 1.01$)$ & $0.06^{\mathrm{a}}$ & & $1.31(0.91 \text { to } 1.88)^{\mathrm{a}}$ & $0.15^{\mathrm{a}}$ & \\
\hline Diet/eating habits attribution, yes & 0.72 (0.42 to 1.24$)$ & 0.23 & & $1.61(1.02 \text { to } 2.55)^{\mathrm{a}}$ & $0.040^{\mathrm{a}}$ & \\
\hline
\end{tabular}

indicate that more personal control can result in more positive expectations regarding the course of the fatigue and, subsequently, in better outcomes.

The prognostic value of patient expectations might explain why psychological symptoms were not retained in the models. Previous studies that reported associations of psychological symptoms with fatigue outcome did not measure illness-related perceptions. ${ }^{21,28}$ Likewise, contrary to findings from other studies, ${ }^{9,25-27}$ patient attributions were not retained in this study's models. This might be partly explained by the fact that patients often have mixed attributions; an exclusively somatic illness attribution may have more predictive value than the presence of a psychological attribution. More importantly, patient attributions may be related to expectations of chronicity. These catastrophising perceptions were consistently retained in both models, and were apparently more important in predicting outcome in this study's population.

Apart from psychological symptoms, the number of other physical symptoms and pain intensity were also related to a poor outcome, whereas better perceived health was related to a favourable outcome. These results are in line with the results of studies among employees with fatigue. ${ }^{26,29}$

Female sex, providing informal care, and more (severe) prolonged difficulties were included in the combination of factors that were inversely associated with a fast recovery. This seems to 
Table 3 continued. Predictors of outcome in patients presenting with fatigue in general practice.

\begin{tabular}{|c|c|c|c|c|c|c|}
\hline & \multicolumn{3}{|c|}{ Favourable course, $n=561$} & \multicolumn{3}{|c|}{ Unfavourable course, $n=535$} \\
\hline & $\begin{array}{l}\text { Univariate OR } \\
\quad(95 \% \mathrm{Cl})\end{array}$ & $P$-value ${ }^{a}$ & $\begin{array}{c}\text { Multivariate OR } \\
(95 \% \mathrm{Cl}), \text { AUC } 0.79\end{array}$ & $\begin{array}{l}\text { Univariate OR } \\
\quad(95 \% \mathrm{Cl})\end{array}$ & $P$-value ${ }^{a}$ & $\begin{array}{c}\text { Multivariate OR } \\
(95 \% \mathrm{Cl}), \mathrm{AUC} 0.80\end{array}$ \\
\hline \multicolumn{7}{|l|}{ Health and other symptoms } \\
\hline Better perceived health, SF-36, ppi & $1.03(1.02$ to 1.05$)$ & $<0.001^{\mathrm{a}}$ & 1.01 (1.00 to 1.03$)$ & $0.97(0.96 \text { to } 0.98)^{\mathrm{a}}$ & $<0.001^{\mathrm{a}}$ & \\
\hline Less pain, SF-36, ppi & 1.02 (1.01 to 1.03$)$ & $<0.001^{\mathrm{a}}$ & & $0.97(0.97 \text { to } 0.98)^{\mathrm{a}}$ & $<0.001^{\mathrm{a}}$ & 0.98 (0.97 to 0.99$)$ \\
\hline Distress, 4DSQ, ppi & 0.93 (0.91 to 0.96$)$ & $<0.001^{\mathrm{a}}$ & & $1.06(1.04 \text { to } 1.09)^{a}$ & $<0.001^{\mathrm{a}}$ & \\
\hline Depression, 4DSQ, ppi & 0.86 (0.78 to 0.95$)$ & $0.002^{\mathrm{a}}$ & & $1.21(1.12 \text { to } 1.30)^{\mathrm{a}}$ & $<0.001^{\mathrm{a}}$ & \\
\hline Anxiety, 4DSQ, ppi & 0.87 (0.81 to 0.94$)$ & $<0.001^{\mathrm{a}}$ & & $1.10(1.05 \text { to } 1.16)^{\mathrm{a}}$ & $<0.001^{a}$ & \\
\hline Somatisation, 4DSQ, ppi & 0.91 (0.88 to 0.95$)$ & $<0.001^{\mathrm{a}}$ & & $1.10(1.07 \text { to } 1.13)^{\mathrm{a}}$ & $<0.001^{\mathrm{a}}$ & \\
\hline \multicolumn{7}{|l|}{ Sleep problems, SCL-90 } \\
\hline Above average versus low or average & $1.10(0.64$ to 1.89$)$ & 0.73 & & 0.81 (0.49 to 1.33$)$ & 0.40 & \\
\hline High versus low or average & 0.82 (0.51 to 1.30$)$ & 0.39 & & $1.22(0.81$ to 1.83$)$ & 0.34 & \\
\hline $\begin{array}{l}\text { Number of experienced symptoms since } \\
\text { start of fatigue, IPQ-R }\end{array}$ & 0.85 (0.78 to 0.92$)$ & $<0.001^{a}$ & & $1.14(1.07 \text { to } 1.22)^{\mathrm{a}}$ & $<0.001^{\mathrm{a}}$ & \\
\hline
\end{tabular}

\section{Social factors and lifestyle}

Number of days of moderate intensity physical

activity for at least 30 minutes, SQUASH

Continuous

$1.07(0.99$ to 1.16$) \quad 0.11^{\mathrm{a}}$

$1-5$ days versus 0 days

$5-7$ days versus 0 days

$0.81(0.53$ to 1.26$) \quad 0.35$

Physical activity of vigorous intensity in work, school or household, SQUASH

\begin{tabular}{lllll}
$<5$ hours versus no & $1.08(0.68$ to 1.71$)$ & 0.74 & $0.82(0.54$ to 1.25$)$ & 0.36 \\
$\geq 5$ hours versus no & $0.72(0.44$ to 1.17$)$ & 0.18 & $0.99(0.66$ to 1.49$)$ & 0.97 \\
\hline
\end{tabular}

\begin{tabular}{lllll}
\hline Enjoying daily activities, yes & $1.88(1.20$ to 2.94$)$ & $0.005^{\mathrm{a}}$ & 0.60 (0.42 to 0.87$)$ & $0.006^{\mathrm{a}}$
\end{tabular}

\begin{tabular}{lllll}
\hline Mentally strenuous daily activities, yes & $0.83(0.56$ to 1.24$)$ & 0.37 & $1.13(0.80$ to 1.60$)$ & 0.50
\end{tabular}

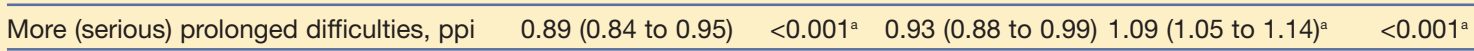

Life events

1 versus 0

$\geq 2$ versus 0

$1.03(0.62$ to 1.73$) \quad 1.03$

0.81 (0.51 to 1.31$) \quad 0.81$

Less social support, SOS, ppi

0.96 (0.93 to 0.98$) \quad 0.002^{2}$

Alcohol, number of glasses in

1.11 (0.97 to 1.28$) \quad 0.14^{\mathrm{a}}$

$0.97(0.62$ to 1.53$) \quad 0.90$

$1.20(0.80$ to 1.82$) \quad 0.38$

5 categories; per category

Smoking, daily versus

$0.76(0.46$ to 1.25$)$

0.27

$1.05(1.03 \text { to } 1.07)^{\mathrm{a}}$

$<0.001^{\mathrm{a}}$

1.03 (1.01 to 1.06$)$

sometimes, ever or never

anivariate $P$ values $<0.20$ were selected for multivariate analysis. $\mathrm{OR}=$ odds ratio. $\mathrm{Cl}=$ confidence interval. $A \cup C=$ area under the receiver operating characteristic curve. CIS = Checklist Individual Strength. ppi = per point increase. IPQ-R = IIIness Perception Questionnaire - Revised. SF-36 = Short Form health survey - 36. $4 D S Q=$ Four-Dimensional Symptom Questionnaire. SCL = Symptom Checklist. SQUASH = Short QUestionnaire to ASsess Health-enhancing physical activity. SOS = Social Support Scale.

indicate a negative influence of higher levels of external demands. Caring for young children has been reported to be associated with fatigue in a cross-sectional nationwide study, ${ }^{30}$ and can be a sexspecific indication of more responsibilities, but such an association was not found longitudinally. However, although less frequent in the present study population, providing informal care for other (ill or older) adults was a significant predictor. It could be hypothesised that taking care of children is generally a choice or a planned responsibility that takes place in another phase of life, and therefore might be perceived as less distressful or tiring.

A majority of $82 \%$ of the participants in this study reported that they experienced prolonged difficulties, and $17 \%$ experienced severe difficulties in at least one area. The associations of prolonged difficulties and social support with outcome are in line with studies among patients with chronic fatigue syndrome, showing that negative interactions or insufficient support contribute to the persistence of symptoms, ${ }^{31}$ and that negative or serious difficulties were more frequent in the months preceding the onset of chronic fatigue syndrome. ${ }^{32,33}$ Furthermore, enjoying daily activities was univariately associated with a positive outcome in the current study, while the number of life events was not associated with a negative outcome. These findings would support the 
notion that perceived quality or intensity of activities or events may be more important than their number in contributing to the (im)balance between perceived demands and resources in patients with fatigue.

\section{Implications for future research and clinical practice}

Patient perceptions are associated with the prognosis of fatigue in primary care. Negative thoughts regarding symptoms are potentially modifiable in patients, and evaluation of the effectiveness of targeted interventions should be addressed in future research among patients presenting with fatigue in general practice. In the meantime, when taking a patient's history, GPs should pay attention to the presence of negative perceptions in patients who present with fatigue to identify those who are already at risk of a poor outcome at the time of the initial assessment.

\section{Funding body}

VU University Medical Centre

\section{Ethics committee}

Medical Ethics Committee of the VU University Medical Centre, Amsterdam, The Netherlands (04-042)

\section{Competing interests}

The authors have stated that there are none

\section{Acknowledgements}

We thank all participating patients and GPs for their contribution to this study.

\section{Discuss this article}

Contribute and read comments about this article on the Discussion Forum: http://www.rcgp.org.uk/bjgp-discuss

\section{REFERENCES}

1. Cullen W, Kearney Y, Bury G. Prevalence of fatigue in general practice. Ir J Med Sci 2002; 171(1): 10-12.

2. Kenter EG, Okkes IM, Oskam SK, Lamberts H. Tiredness in Dutch family practice. Data on patients complaining of and/or diagnosed with 'tiredness'. Fam Pract 2003; 20(4): 434-440.

3. Nelson E, Kirk J, McHugo G, et al. Chief complaint fatigue: a longitudinal study from the patient's perspective. Fam Pract Res J 1987; 6(4): 175-188.

4. Sharpe M, Wilks D. Fatigue (ABC of psychological medicine: Fatigue). BMJ 2002; 325(7362): 480-483.

5. Cathebras PJ, Robbins JM, Kirmayer LJ, Hayton BC. Fatigue in primary care: prevalence, psychiatric comorbidity, illness behavior, and outcome. J Gen Intern Med 1992; 7(3): 276-286.

6. Ridsdale L, Evans A, Jerrett W, et al. Patients with fatigue in general practice: a prospective study. BMJ 1993; 307(6896): 103-106.

7. Nijrolder I, Van der Windt DAWM, Van der Horst HE. Prognosis of fatigue. A systematic review. J Psychosom Res 2008; 64(4): $335-349$.

8. Vercoulen JHMM, Alberts M, Bleijenberg G. De Checklist Individual Strength (CIS) [in Dutch]. Gedragstherapie 1999; 32(2): 131-136.

9. Huibers MJ, Bultmann U, Kasl SV, et al. Predicting the two-yea course of unexplained fatigue and the onset of long-term sicknes absence in fatigued employees: results from the Maastricht Cohort Study. J Occup Environ Med 2004; 46(10): 1041-1047.

10. Servaes P, van der WS, Prins J, et al. Fatigue in disease-free cancer patients compared with fatigue in patients with chronic fatigue syndrome. Support Care Cancer 2001; 9(1): 11-17.

11. Moss-Morris R, Weinman J, Petrie KJ, et al. The Revised Illness Perception Questionnaire (IPQ-R). Psychology and Health 2002;
17: $1-16$.

12. Terluin B, van Marwijk HW, Ader HJ, et al. The Four-Dimensional Symptom Questionnaire (4DSQ): a validation study of a multidimensional self-report questionnaire to assess distress, depression, anxiety and somatization. BMC Psychiatry 2006; 6: 34

13. Arrindell WA EJ. SCL-90: handleiding bij een multidimensionele psychopathologie-indicator [User Manual, in Dutch]. Lisse: Swets Test Services, 1986.

14. Van der Zee K, Sanderman R, Heyink J. De psychometrische kwaliteiten van de MOS-36-item Short Form health Survey [SF36] in een Nederlandse populatie [in Dutch]. T Soc Gezondheidsz 1993; 71: 183-191.

15. Wendel-Vos GC, Schuit AJ, Saris WH, Kromhout D. Reproducibility and relative validity of the short questionnaire to assess health-enhancing physical activity. J Clin Epidemiol 2003; 56(12): 1163-1169.

16. Hendriks A, Ormel J, Willige G. Long-term difficulties measured with self-report questionnaire and semi-structured interview [in Dutch]. Gedrag en Gezondheid 1990; 18: 273-283.

17. Feij J, Doorn C, Van Kampen D, et al. Sensation seeking and social support as moderators of the relationship between life events and physical illness/psychological distress. In: Winnubst JAM, Maes S (eds). Lifestyles, stress and health. Leiden: DSWO Press, 1992; 285-302.

18. Hosmer DW, Lemeshow S. Assessing the fit of the model. In: Hosmer DW, Lemeshow S (eds). Applied logistic regression. New York: John Wiley \& Sons, 1989; 135-175.

19. Harrell FE Jr, Lee KL, Mark DB. Multivariable prognostic models: issues in developing models, evaluating assumptions and adequacy, and measuring and reducing errors. Stat Med 1996; 15(4): $361-387$.

20. Steyerberg EW, Harrell FE Jr, Borsboom GJ, et al. Interna validation of predictive models: efficiency of some procedures for logistic regression analysis. J Clin Epidemiol 2001; 54(8): 774-781.

21. Skapinakis P, Lewis G, Mavreas V. One-year outcome of unexplained fatigue syndromes in primary care: results from an international study. Psychol Med 2003; 33(5): 857-866.

22. Eriksen W. Work factors as predictors of persistent fatigue: a prospective study of nurses' aides. Occup Environ Med 2006; 63(6): 428-434.

23. Taylor RR, Jason LA, Curie CJ. Prognosis of chronic fatigue in a community-based sample. Psychosom Med 2002; 64(2): 319-327.

24. Clark MR, Katon W, Russo J, et al. Chronic fatigue: risk factors for symptom persistence in a $21 / 2$-year follow-up study. Am J Med 1995; 98(2): 187-195

25. Chalder T, Godfrey E, Ridsdale L, et al. Predictors of outcome in a fatigued population in primary care following a randomized controlled trial. Psychol Med 2003; 33(2): 283-287.

26. Huibers MJ, Bleijenberg G, van Amelsvoort LG, et al. Predictors of outcome in fatigued employees on sick leave: results from a randomised trial. J Psychosom Res 2004; 57(5): 443-449.

27. Vercoulen JH, Swanink CM, Fennis JF, et al. Prognosis in chronic fatigue syndrome: a prospective study on the natural course. $J$ Neurol Neurosurg Psychiatry 1996; 60(5): 489-494.

28. Hickie I, Koschera A, Hadzi-Pavlovic D, et al. The temporal stability and co-morbidity of prolonged fatigue: a longitudinal study in primary care. Psychol Med 1999; 29(4): 855-861.

29. Huibers MJ, Kant IJ, Knottnerus JA, et al. Development of the chronic fatigue syndrome in severely fatigued employees: predictors of outcome in the Maastricht cohort study. J Epidemiol Community Health 2004; 58(10): 877-882.

30. Cardol M, Bensing J, Verhaak P, Bakker D. Fatigue: determinants, course and care [Moeheid: determinanten, beloop en zorg] [in Dutch]. Utrecht: Nivel, 2005.

31. Prins JB, Bos E, Huibers MJ, et al. Social support and the persistence of complaints in chronic fatigue syndrome. Psychother Psychosom 2004; 73(3): 174-182.

32. Hatcher S, House A. Life events, difficulties and dilemmas in the onset of chronic fatigue syndrome: a case-control study. Psychol Med 2003; 33(7): 1185-1192.

33. Theorell T, Blomkvist V, Lindh G, Evengard B. Critical life events, infections, and symptoms during the year preceding chronic fatigue syndrome (CFS): an examination of CFS patients and subjects with a nonspecific life crisis. Psychosom Med 1999; 61(3): 304-310. 